\title{
中国农产品国际竞争力及其影响因素分析
}

\author{
易佶仙 史晓娟 \\ 成都信息工程大学 \\ DOI:10.32629/as.v3i3.1822
}

\begin{abstract}
[摘要] 随着我国农业 “走出去” 战略的推进,我国农产品国际化参与度不断提高,为挖掘我国农产品对 外贸易潜力,基于波特 “钻石模型”, 分析我国农产品国际竞争力的影响因素, 为提高我国农产品的国际 竞争力提出合理建议。
\end{abstract}

[关键词] 农产品; 国际竞争力; 钻石模型

中图分类号: F762 文献标识码: A

随着我国农业 “走出去” 战略推 进, 农产品国际化参与度不断提高, 为 挖掘我国农产品贸易潜力, 应明确我 国农产品国际竞争力的影响因素, 探 寻相应对策。

\section{1 中国农产品国际竞争力分析}

从不同角度对国际竞争力有不同的 评价指标, 基于评价指标的可比性和可 测量性, 本文选用以下三个评价指标对 中国农产品国际竞争力进行分析。

1. 1 国际市场占有率 (IMS)

国际市场占有率是指一国某类产品 出口总额占世界同类产品出口总额的比 重。国际竞争力的强弱与IMS值成正比 ${ }^{[1]}$, 具体判定标准是：IMS< $<5$, 很弱; $5 \%<\mathrm{IMS}<10 \%$, 一般; $10 \%<\mathrm{IMS}<20 \%$, 较强; IMS $>20 \%$, 很强。中国农产品的IMS在 2013 年之前小于 $5 \%, 2014$ 年打破 $5 \%$ 的限制 后, IMS总体呈上升趋势。根据IMS指标可 以断定, 中国农产品国际竞争力已由很 弱变成一般, 说明中国农产品国际竞争 力有所提升。

\section{2 贸易竞争指数 (TC)}

贸易竞争指数是指一国某类产品净 出口额占该类产品贸易进出口总额的比 重。总的来说, TC>0说明该国这类产品的 竞争力相对较高; $\mathrm{TC}<0$ 说明该国这类产 品的竞争力相对较弱。具体判定标准是: $-1 \leqslant \mathrm{TC}<-0.8$, 劣势很高; $-0.8 \leqslant \mathrm{TC}<-0.5$, 劣势较高; $-0.5 \leqslant \mathrm{TC}<0$, 略有劣势; $0 \leqslant$ $\mathrm{TC}<0.5$, 优势中等; $0.5 \leqslant \mathrm{TC}<0.8$, 优势较
高; $0.8 \leqslant \mathrm{TC} \leqslant 1$, 优势很高。中国农产品 的TC在 2011 年至 2017 年从 $-0.219 \%$ 上升 到 $-0.248 \%$, 根据TC指标可以断定, 中国 农产品国际竞争力上略有劣势, 虽然近 年来TC指标有所增加, 但仍为负数, 说明 中国农产品贸易的竞争优势不大, 农产 品生产与出口的水平仍较低。

1. 3显示性比较优势指数 (RCA)

显示性比较优势指数是指一国某类 商品出口额占该国出口总额的比重与世 界各国此类商品出口额占世界出口总额 的比重的比率。一般来说, RCA越大某国该 产品出口越多, 具有比较优势; 反之则具 有比较劣势。具体判定标准为: RCA $\leqslant 0.8$, 较弱; $0.8<\mathrm{RCA} \leqslant 1.25$, 中等; $1.25<\mathrm{RCA}$ $\leqslant 2.5$, 较强; RCA $>2.5$, 极强。中国农产品 的RCA从 2011 年至 2015 年由 $0.44 \%$ 下降到 0. $4 \%$, 较为薄弱的竞争优势逐渐下滑, 比 较劣势缓慢恶化, 从2016年至2017年有所 回升, 比较劣势恶化的情况得到缓解, 但 在国际上的竞争力依旧较弱。

\section{2 中国农产品国际竞争力的影} 响因素

迈克尔・波特的 “钻石模型” 认为, 生产要素、需求情况、相关及支持产业、 结构及竞争、政府和偶然因素等要素共 同决定一国某种产业或产品的竞争力 ${ }^{[2]}$, 本文基于 “钻石模型” 来分析我国农产 品国际竞争力的影响因素。

2. 1 生产要素

我国耕地面积占世界的 $4.85 \%$, 人均
耕地面积却未及世界平均水准的一半, 只有 0.0009 。农业劳动力资源较为充足, 随着城市化的推进, 农村劳动力长期转 移, 青壮年高素质的劳动力多选择外出 打工, 农业经营人员以小学、初中文化程 度的 36 岁以上男性为主体。他们年龄较 大, 缺乏足够体力, 对土地基本采取粗放 经营, 而教育程度偏低, 缺少相应科技知 识, 高新技术难以推广和运用 ${ }^{[3]}$ 。

\section{2 需求条件}

我国人口多, 粮食需求大, 粮食生产 不断实现的增产与进步, 很大程度是完 成粮食的刚性需求, 使我国粮食剩余产 品较少, 出口量少, 难以形成竞争优势。 随着我国经济增长, 居民消费需求发生 了改变, 但对农产品的需求仍主要是鲜 活、美味, 导致农业加工企业没有足够的 动力来进行创新。

\section{3 相关与支持产业}

上游产业中, 存在过量使用农药化 肥问题, 使农产品农药超标, 出口易遭遇 贸易壁垒。我国海岸线长达 1.8 万 $\mathrm{km}$, 在 2017年港口吞吐量实现143.5亿吨, 优越 的港口资源能节约贸易运输成本, 加快 运输时效, 让中国农产品以最佳状态出 现在国际市场上, 增加竞争力。下游产业 中, 龙头企业与农业合作社的新式营业 模式在持续扩展, 促进了现代农业的建 设与发展。因农产品对包装、储存和运 输条件要求严格, 虽然我国农产品运输 流量规模超过 4 万亿元, 但冷链运输年度 
流量不足 3 千亿元, 冷链流通普及率远不 及 $50 \%$, 流通中损耗率较高。

2. 4企业战略、结构及竞争

我国林业、畜牧业和渔业虽然发展 迅速, 但种植业始终占据农业核心地位, 在2019年的农业内部结构中占比仍超过 $50 \%$ 。随着产业结构及国内需求变化, 决 定了我国农产品企业战略为出口果蔬类 产品、畜产品及水产品, 农业生产资源主 要倾斜给种植业。因本国消费及战略储 备需求, 粮食出口有一定限制, 而主要出 口品类受到的支持力度不够, 导致我国 农产品国际竞争力较弱。

在国内竞争环境中, 企业会为赢得市 场而积极创新并抢占国际市场。农产品企 业为保证在竞争中生存会关注农产品价 格、质量及品质, 这可间接提高农产品的 质量, 利于提高农产品国际竞争力。在国 际竞争环境中, 贸易壁垒是农产品同业竞 争的主要表现。贸易保护主义藏匿在各国 非关税措施下, 使农产品国际市场处于高 补贴、高关税和高壁垒的状态, 这不利于 我国农产品出口贸易的发展。

\section{5 政府}

我国政府在对内支持政策上一直重 视农业的发展, 在2006年就取消了农业 税、屠宰税和牧业税, 不断增强对农业的 扶持, 降低生产成本, 调动农民生产积极 性, 为农业提供更好的发展环境。在对外 贸易政策上积极发挥宏观调控作用, 增 强优势产品出口, 使贸易规模达到平衡

状态。

2. 6 偶然因素

我国农业工业化生产未全面推广， 抗灾能力较低, 不利于农业生产, 但敏 锐抓住一些偶然因素, 也会刺激农业迅 速发展。如现在新型冠状病毒影响各国 农业, 国际市场农产品需求明显增加, 我国反应迅速, 很快控制疫情率先复工, 抓住了增强我国农产品国际竞争力的 这个机会。

\section{3 提升我国农产品国际竞争力}

\section{的对策建议}

3. 1 优化农业经营结构

对农产品生产、加工、运输、销售 进行统一管理, 推广机械化生产和企业 管理模式, 减少不必要的成本支出和农 业新技术的推广阻力。加强建设农业行 业协会, 提供农业交易信息平台, 实时更 新国内外农产品交易资讯, 减少因信息 传达滞后造成的损失。

3.2 提高农业劳动力的文化水平

继续普及农业基础教育, 推广农业 职业教育, 进一步提高农民受教育年限, 只有提高农民文化水平才能有效应用与 推广新的种植技术。此外还可建立农业 技术教育机构, 定期组织学习最新农业 种植技术与培育方法, 推广科学管理模 式, 帮助农民利用现代科技获得相关学 习知识, 拓展农产品销售途径。

3. 3 完善农业物流运输系统

加快建设农产品冷藏库, 提高冷链
运输在农产品运送中的运用, 减少物流 的损耗, 保证产品的出口质量, 有效规避 严苛的入关检测标准。同时要加强供应 链的建设, 利用 “互联网+”进行跨境电 商交易, 让消费者和供应者连接起来, 有 助于企业突破贸易壁垒, 提高市场开发 效率。

3. 4 发挥政府 “有形的手”

适度的市场竞争有利于产业发展, 但过度竞争需要政府进行调控, 建立完 善农业市场机制, 消除地方保护, 使各主 体都能在市场中公平有序经营, 避免“恶 性竞争”。

\section{5 调整出口市场结构}

必须深层次开拓国际农产品市场, 使出口市场多元化, 同时政府应积极收 集国际标准, 建立专门的数据库, 加快建 设我国农产品出口预警机制, 预测市场 风险, 定期发布风险预警, 以降低我国农 业企业的出口风险, 保障我国农产品顺 利进入国际市场。

\section{[参考文献]}

[1]赵长和.中国和印度茶叶出口竞 争力比较[J]. 重庆理工大学学报: 社会科 学版,2016(11):82-87.

[2]迈克尔・波特[美].国家竞争优势 [M].中信出版社,2007.

[3]胡友,祁春节.中国柑橘国际竞争 力动态演变及其影响因素实证研究 [J]. 华中农业大学学报,2013(06):33-38. 